\title{
Kinetics of nitrification and acrylamide biodegradation by Enterobacter aerogenes and mixed culture bacteria in sequencing batch reactor wastewater treatment systems
}

\author{
Romsan Madmanang1, Siriprapha Jangkorn ${ }^{2}$, Jittima Charoenpanich ${ }^{3}$, Tongchai Sriwiriyarat ${ }^{4^{\dagger}}$ \\ ${ }^{1}$ Environmental Science Program, Faculty of Science, Burapha University, Chonburi 20131, Thailand \\ ${ }^{2}$ Division of Natural Resources and Environment, Faculty of Science and Social Sciences, Burapha University, Sakaeo 27160, Thailand \\ ${ }^{3}$ Department of Biochemistry, Faculty of Science, Burapha University, Chonburi 20131, Thailand \\ ${ }^{4}$ Department of Chemical Engineering, Faculty of Engineering, Burapha University, Chonburi 20131, Thailand
}

\begin{abstract}
This study evaluated the kinetics of acrylamide (AM) biodegradation by mixed culture bacteria and Enterobacter aerogenes (E. aerogenes) in sequencing batch reactor (SBR) systems with AQUASIM and linear regression. The zero-order, first-order, and Monod kinetic models were used to evaluate the kinetic parameters of both autotrophic and heterotrophic nitrifications and both AM and chemical oxygen demand (COD) removals at different AM concentrations of 100, 200, 300, and $400 \mathrm{mg} \mathrm{AM/L}$. The results revealed that both autotrophic and heterotrophic nitrifications and both AM and COD removals followed the Monod kinetics. High AM loadings resulted in the transformation of Monod kinetics to the first-order reaction for AM and COD removals as the results of the compositions of mixed substrates and the inhibition of the free ammonia nitrogen (FAN). The kinetic parameters indicated that E. aerogenes degraded AM and COD at higher rates than mixed culture bacteria. The FAN from the AM biodegradation increased both heterotrophic and autotrophic nitrification rates at the AM concentrations of 100-300 mg $\mathrm{AM} / \mathrm{L}$. At higher AM concentrations, the FAN accumulated in the SBR system inhibited the autotrophic nitrification of mixed culture bacteria. The accumulation of intracellular polyphosphate caused the heterotrophic nitrification of E. aerogenes to follow the first-order approximation.
\end{abstract}

Keywords: Acrylamide biodegradation, Ammonia inhibition, Biodegradation kinetics, Enterobacter aerogenes

\section{Introduction}

Acrylamide (AM, $\mathrm{C}_{3} \mathrm{H}_{5} \mathrm{NO}$ ) monomer is a chemical compound that is used for synthesizing various polymers such as polyacrylamides (PAMs), which have been used widely as flocculants for water and sewage treatments, adhesives, and others. However, it has been documented that AM is a neurotoxicant, carcinogen, and hazardous substance, causing irritation and toxicity in human. Thus, the AM concentration is limited to $0.05 \%(w / w)$ in the commercial PAMs, and the PAMs application dosage of less than $1.0 \mathrm{mg} / \mathrm{L}$ is only allowed [1]. The production and application of AM such as in the production of PAMs could contaminate the environment [1-2]. Due to its adverse effects, the contamination of $\mathrm{AM}$ in the wastewater must be eliminated. Most of the previous studies have focused on microbial isolation and AM biodegradation with pure culture of bacteria in the laboratory including Arthrobacter sp., Nocardia sp., Bacillus sp., Xanthomonas sp., Rhodopseudomonas sp., Rastonia sp., Geobacillus sp., Pseudomonas sp., and Rhodococcus sp. [2-4]. Recently, Enterobacter aerogenes (E. aerogenes) was reported as a bacterium with high capability to biodegrade $\mathrm{AM}$ in the culture media at a concentration as high as 5,000 mg AM/L [5]. E. aerogenes, formerly known as Aerobacter aerogenes [6], is a facultative and mesophilic bacterium [7] and is capable to heterotrophically nitrify ammonium nitrogen under aerobic condition [8]. Jangkorn et al. [9] conducted the experiments to compare AM biodegradations of E. aerogenes, mixed culture bacteria, and a mixture of both bacteria in the biological wastewater treatment sequencing batch reactor (SBR)
This is an Open Access article distributed under the terms of the Creative Commons Attribution Non-Commercial License (http://creativecommons.org/licenses/by-nc/3.0/) which permits unrestricted non-commercial use, distribution, and reproduction in any medium, provided the original work is properly cited.

Copyright (C) 2019 Korean Society of Environmental Engineers
Received May 30, 2018 Accepted August 7, 2018

${ }^{\dagger}$ Corresponding author Email: sriwiri@buu.ac.th Tel: +66-3810-3352

ORCID: 0000-0001-7348-6847 
systems operating at the solids retention time (SRT) of $10 \mathrm{~d}$ and hydraulic retention time (HRT) of $24 \mathrm{~h}$. It was found that $E$. aerogenes, which was reported to biodegrade the AM substantially in the laboratory [5], did not biodegrade AM efficiently in the SBR wastewater treatment systems.

With amidase as a catalyst of the deamination reaction for the AM biodegradation, both ammonia nitrogen and acrylic acid (AA) as the biodegradation products were produced [2-4]. Both AA and ammonia would potentially contribute organic matter and nitrogen to the wastewater, respectively; therefore, carbon oxidation of AA and nitrification would be required to meet the effluent standards. Jangkorn et al. [9] found that both ammonia and AA were considerably accumulated in the SBR activated sludge (AS) treatment systems containing $E$. aerogenes and mixed culture bacteria under aerobic condition. They also reported that ammonia inhibited the AM biodegradation and nitrification in the SBR systems. These findings suggest that AM and its biodegradation products are possible to interfere with the carbon removal and nitrification in the biological wastewater treatment process.

The knowledge of kinetics is essential to evaluate the biological degradation of substrates in the biological wastewater treatment system. The kinetics of hydrolyzed polyacrylamide (HPAM) biodegradation, carried out in the batch experiments containing different initial HPAM concentrations and both Bacillus cereus and Bacillus sp. obtained from a sequencing batch biofilm reactor (SBBR) under the aerobic condition, revealed that the maximum HPAM biodegradation rate $\left(\mathrm{V}_{\max }\right)$ and Michaelis-Menten constant $\left(\mathrm{K}_{\mathrm{m}}\right)$ were $16.4 \mathrm{mg} / \mathrm{L}$-day and $579 \mathrm{mg} \mathrm{HPAM} / \mathrm{L}$, respectively [10]. However, the kinetics could not be applied to the AM biodegradation due to differences in microorganisms, substrate types and concentrations, and biological wastewater treatment systems. The kinetics of AM biodegradation under aerobic condition by the mixed culture bacteria and E. aerogenes in the biological wastewater treatment systems have not yet been reported. In addition, the effects of AM on the chemical oxygen demand (COD) removal and nitrification kinetics as a result of the AM biodegradation have not been addressed. This study reported the effects of AM on the COD removal and nitrification kinetics of both mixed culture bacteria and E. aerogenes in the SBR systems.

\section{Materials and Methods}

\subsection{Experimental Data of AM Biodegradation Studies in SBR Systems}

Substrate removal data from the AM biodegradation studies during the reacting periods of the SBR systems [9] were used to evaluate the COD removal and nitrification kinetics, the AM biodegradation kinetics, and effects of AM on the both COD removal and nitrification kinetics. Two SBR biological wastewater treatment systems containing mixed culture bacteria and E. aerogenes called as AM-1 and AM-2 were used for degrading AM in the synthetic wastewater containing organic matters indicated as total chemical oxygen demand (TCOD) of about $400 \mathrm{mg}$ COD/L, ammonium nitrogen of about $43.5 \mathrm{mg} \mathrm{N} / \mathrm{L}$, and phosphorus of about 7-8 mg P/L [9]. E. aerogenes was isolated and cultured from the Department of Biochemistry (Burapha University, Thailand) and mixed culture bacteria was taken from a pilot-scale Modified Ludzack-Ettinger (MLE) wastewater treatment system running in the Department of Chemical Engineering (Burapha University) for biological nitrogen removal. AM was fed to the AM-1 and AM-2 systems at the concentrations of 100, 200, 300, and 400 $\mathrm{mg} \mathrm{AM} / \mathrm{L}$ along with other carbon sources to obtain the TCOD of $400 \mathrm{mg}$ COD/L during the first, second, third, and fourth weeks of experiments, respectively. AM was used as a sole carbon source during the AM feeding concentration of $400 \mathrm{mg} \mathrm{AM} / \mathrm{L}$. The total nitrogen of synthetic wastewater containing both AM and ammonium nitrogen was not measured in this study, but could be calculated from the stoichiometric relationship between AM and ammonia. According to the stoichiometric molar ratio of AM to ammonia (1:1), complete AM biodegradation could contribute nitrogen in the wastewater at the concentrations of 19.7 [(100 $\mathrm{mg} \mathrm{AM} / \mathrm{L} / 71.08 \mathrm{mg} \mathrm{AM} / \mathrm{mmole}) \times 14 \mathrm{mg} \mathrm{N} / \mathrm{mmole}]$, 39.4, 59.1, and $78.7 \mathrm{mg} \mathrm{N} / \mathrm{L}$ when $\mathrm{AM}$ was added the concentrations of 100, 200, 300, and $400 \mathrm{mg} \mathrm{AM/L}$, respectively. Other two SBR systems referred to as Control-1 and Control-2 systems containing mixed culture bacteria and $E$. aerogenes, respectively, were used as the control systems, feeding with only synthetic wastewater without any AM substitution. Each SBR system, with a working volume of $3.0 \mathrm{~L}$, was operated with two cycles per day at the nominal HRT of $24 \mathrm{~h}$, the operating SRT of $10 \mathrm{~d}$, and the temperature of about $28^{\circ} \mathrm{C}$. Upon achieving the quasi-steady state conditions, the biomass concentrations in the Control-1, Control-2, AM-1, and AM-2 systems were about 2,648 \pm 172, $266 \pm 8$, $2,663 \pm 139$, and $295 \pm 30 \mathrm{mg} \mathrm{VSS} / \mathrm{L}$, respectively.

\subsection{Determination of Kinetic Parameters}

Several mathematical expressions are available including first-order, Monod growth, co-metabolisms, second-order, and Michaelis-Menten kinetics to describe the kinetics of biodegradation in aquatic environment [11]. However, the Monod model is widely used for a single bacterial species growing on a single limiting substrate resulting in the microbial growth. When substrate concentration $(S)$ is several times greater than the half saturation coefficient $\left(\mathrm{K}_{\mathrm{S}}\right)$, the Monod equation is simplified to the zero-order rate expression. However, when the substrate concentration is much less than the $\mathrm{K}_{\mathrm{S}}$, the biodegradation rate can be approximated by the first-order equation. In the wastewater treatment practices, wastewater typically contains a mixture of several organic substrates and is measured as the nonspecific substrate parameter such as COD or BOD. Monod model is still applicable to evaluating the biodegradation kinetics of nonspecific substrate parameters for the mixed culture bacteria [12]. Alexander [13] proposed the integrated Monod equations consisting of six biodegradation kinetic models; among them, three biodegradation models are used for non-growing microorganisms including zero-order, first-order, and Monod (no growth) models as shown in Eq. (1)-(3), respectively. Monod kinetic model for non-growing microorganisms was appropriate for this study because the SBR systems were controlled at the SRT of $10 \mathrm{~d}$; thus, approximate constant biomass concentrations were obtained. It is known that 
the net daily sludge production or bacterial growth is limited to about the one tenth of total biomass because of the controlled operating SRT of $10 \mathrm{~d}$.

$$
\begin{gathered}
\mathrm{d} S / \mathrm{d} t=-k_{2} \\
\mathrm{~d} S / \mathrm{d} t=-k_{1} \cdot S \\
\mathrm{~d} S / \mathrm{d} t=-k_{2} \cdot S /\left(K_{\mathrm{s}}+S\right)
\end{gathered}
$$

The $k_{2}$ in both Eq. (1) and (3) is the zero-order rate constant and maximum biodegradation rate constant with a unit of mg/L-h. In Eq. (2), $k_{1}$ is the first-order rate constant with a unit of $\mathrm{h}^{-1}$.

Microsoft Excel with linear regression analysis was used to analyze for the zero-order and first-order kinetic models and the fitness was indicated by the coefficient of determination or R-squared $\left(\mathrm{R}^{2}\right)$ value. The graphical plots of substrate concentration versus time and the natural logarithm of substrate concentration versus time according to the integral forms of zero-order and first-order approximations as listed in Eq. (4)-(5), respectively, were used to evaluate the zero-order and first-order kinetics, respectively.

$$
\begin{gathered}
S=S_{\mathrm{o}}-k_{2} \cdot t \\
S=S_{\mathrm{o}} \exp \left(-k_{1} \cdot t\right)
\end{gathered}
$$

In Eq. (4) and (5), $S_{o}$ is the initial substrate concentration (mg/L). The Monod kinetic parameters of $\mathrm{K}_{\mathrm{S}}$ and $\mathrm{k}_{2}$ according to Eq. (3) were estimated by the parameter estimation method of a computer software AQUASIM with the version of $2.1 \mathrm{~g}$ [14], which is widely used simulation and identification of aquatic system. The secant method of AQUASIM estimated the $k_{2}$ and $K_{S}$ by minimizing the Chi-square $\left(\chi^{2}\right)$ value, which is the sum of the squares of the weighted deviations between each experimental data point and the corresponding model prediction. The $\chi^{2}$ was used as a value to indicate the goodness of fit in AQUASIM. The substrate concentrations predicted at different time from estimated parameters were compared with the experimental substrate concentrations. The accuracy of prediction was indicated by the $\mathrm{R}^{2}$-square value.

\section{Results and Discussion}

\subsection{Nitrification and COD Removal in Control SBR Systems}

The experimental results at the quasi-steady state conditions from Jangkorn et al. [9] revealed that the autotrophic nitrification in the Control-1 system was almost completed at the removal efficiency of $98.4 \pm 0.6 \%$ as the results of existing nitrifiers at the SRT of $10 \mathrm{~d}$ and operating at the relative high temperature of about $28^{\circ} \mathrm{C}$. E. aerogenes in the Control-2 system nitrified heterotrophically ammonium nitrogen at the removal efficiency of 65.8 $\pm 26.5 \%$. The heterotrophic nitrification is typically conducted by heterotrophic bacteria; however, energy for ATP production could not be conserved for cell growth [15]. However, a large variation of ammonium concentrations in the Control-2 system was found; therefore, the quasi-steady state conditions with respect to the nitrification could not be achieved. Nitrification in the Control-2 system reduced significantly during the third and fourth weeks of experiments. It was presumed that less energy was available for heterotrophic nitrification due to the accumulation of inorganic polyphosphate in the cells of E. aerogenes. Harold [16] reported that the accumulation of inorganic phosphate was resulted from the competition between polyphosphate and nucleic acid pools for intracellular phosphorus in non-growing cells. Jangkorn et al. [9] explained that the growth of E. aerogenes in the Control-2 system was limited as a result of operating SRT of $10 \mathrm{~d}$; thus, only one-tenth of total biomass was replaced each day with the new growth. Limited growth conditions of $E$. aerogenes possibly resulted in the accumulation of intracellular polyphosphate granules. The experimental results also indicated that both Control-1 and Control-2 systems had approximately the same COD removal efficiencies of $81.1 \pm 0.9$ and $79.3 \pm 1.6 \%$, respectively.

\subsubsection{Kinetics of nitrification}

Both $\mathrm{k}_{2}$ and $\mathrm{K}_{\mathrm{S}}$ Monod kinetic parameters including Chi-squared and R-squared values were obtained from the parameter estimation of AQUASIM and are listed in Table 1 . It was found that the $\mathrm{k}_{2}$ of $16.8 \mathrm{mg} \mathrm{N} / \mathrm{L}-\mathrm{h}$ and $\mathrm{K}_{\mathrm{S}}$ of $33.2 \mathrm{mg} \mathrm{N} / \mathrm{L}$ were obtained with the $\mathrm{R}^{2}$ of 0.999 for the autotrophic nitrification of mixed culture bacteria in the Control-1 system. The maximum specific nitrification rate of mixed culture bacteria, calculated by dividing $\mathrm{k}_{2}$ by the biomass concentration, was $0.15 \mathrm{mg} \mathrm{N} / \mathrm{mg}$ VSS-day. The $K_{S}$ was significantly higher than the typical values of half saturation coefficient (less than $1.0 \mathrm{mg} \mathrm{N} / \mathrm{L}$ ) [17]. It was reported that the $\mathrm{K}_{\mathrm{S}}$ of ammonia-oxidizing bacteria (AOB) could be in the range of 1-100 $\mathrm{mg} \mathrm{N} / \mathrm{L}$, depending on the dominant group of microorganisms in the system [18]. However, the phylogenetic group of the mixed culture bacteria has not been identified in this study.

Table 1 indicates that the $\mathrm{k}_{2}$ of $E$. aerogenes in the Control-2 system was approximately the same as the mixed culture bacteria. However, the maximum specific nitrification rate of $E$. aerogenes was $1.53 \mathrm{mg} \mathrm{N} / \mathrm{mg}$ VSS-day, suggesting that E. aerogenes nitrified at a higher rate than mixed culture bacteria. Furthermore, the $\mathrm{K}_{\mathrm{S}}$ of $E$. aerogenes was much higher than the mixed culture bacteria, indicating that $E$. aerogenes has low affinity for heterotrophic nitrification [19]. It could be implied that the first-order reaction should provide the best goodness of fit for heterotrophic nitrification in the Control-2 system. The first-order reaction rate calculated from the slope of the linear regression of natural logarithm transformed ammonium concentrations values over time was $0.099 \mathrm{~h}^{-1}$ with $\mathrm{R}^{2}$ value of 0.988 . It appears that the ammonium concentrations were best fitted with the first-order reaction. As reported by the experimental results that the quasi-steady state condition with respect to the nitrification in the Control-2 system was not achieved due to the accumulation of intracellular polyphosphate granules. Further biodegradation kinetic evaluations for each week of experiments in the Control-2 system with Monod (no-growth) and first-order kinetics as listed in Table 2 reveal 
Table 1. Monod (no-growth) Kinetic Models for Nitrification and COD Removal of Control-1 and Control-2 Systems

\begin{tabular}{|c|c|c|c|c|c|}
\hline Reactions & SBR System & Parameter & Value & $\mathbf{R}^{2}$ & Chi-squared $\left(\chi^{2}\right)$ \\
\hline \multirow[t]{4}{*}{ Nitrification } & Control-1 & $\mathrm{k}_{2}$ & 16.8 & \multirow{2}{*}{0.999} & \multirow{2}{*}{27.0} \\
\hline & & $\mathrm{K}_{\mathrm{S}}$ & 33.2 & & \\
\hline & \multirow[t]{2}{*}{ Control-2 } & $\mathrm{k}_{2}$ & 16.9 & \multirow{2}{*}{0.998} & \multirow{2}{*}{7.3} \\
\hline & & $\mathrm{K}_{\mathrm{S}}$ & 142.6 & & \\
\hline \multirow[t]{4}{*}{ COD } & \multirow[t]{2}{*}{ Control-1 } & $\mathrm{k}_{2}$ & 71.6 & \multirow{2}{*}{0.996} & \multirow{2}{*}{14.4} \\
\hline & & $\mathrm{K}_{\mathrm{S}}$ & 230.3 & & \\
\hline & \multirow[t]{2}{*}{ Control-2 } & $\mathrm{k}_{2}$ & 84.4 & \multirow{2}{*}{0.996} & \multirow{2}{*}{22.8} \\
\hline & & $\mathrm{K}_{\mathrm{S}}$ & 324.7 & & \\
\hline
\end{tabular}

Table 2. Monod No-growth, Zero-, and First-order Kinetic Models for Nitrification in the Control-2 System during Each Week of Experiments

\begin{tabular}{|c|c|c|c|c|c|}
\hline Types & Week No. & Parameter & Value & $\mathbf{R}^{2}$ & Chi-squared $\left(\chi^{2}\right)$ \\
\hline \multirow[t]{6}{*}{ Monod (no-growth) } & 1 & $\mathrm{k}_{2}$ & 5.3 & \multirow{2}{*}{0.999} & \multirow{2}{*}{2.5} \\
\hline & & $\mathrm{K}_{\mathrm{S}}$ & 8.6 & & \\
\hline & \multirow[t]{2}{*}{2} & $\mathrm{k}_{2}$ & 8.9 & \multirow{2}{*}{0.996} & \multirow{2}{*}{17.5} \\
\hline & & $\mathrm{K}_{\mathrm{S}}$ & 23.3 & & \\
\hline & 3 & * & - & - & - \\
\hline & 4 & * & - & - & - \\
\hline \multirow[t]{4}{*}{ First-order } & 1 & \multirow{4}{*}{$\mathrm{k}_{1}$} & 0.18 & 0.968 & - \\
\hline & 2 & & 0.20 & 0.977 & - \\
\hline & 3 & & 0.08 & 0.966 & - \\
\hline & 4 & & 0.03 & 0.944 & - \\
\hline
\end{tabular}

* indicates unidentified kinetic parameters.

that the Monod (no-growth) model kinetic parameters could be identified only during the first two weeks of experiments. Subsequently, it appears that the $K_{S}$ increased considerably with time from the simulations during the last two weeks of experiments, suggesting that the affinity of E. aerogenes for the ammonium decreased significantly with time due to the accumulation of polyphosphate granules in the cells and less energy was available for heterotrophic nitrification. The first-order approximation is better for the kinetic model. The heterotrophic nitrification during the last two weeks was inhibited as shown by the decrease of first-order rates as shown in Table 2 .

\subsubsection{Kinetics of $\mathrm{COD}$ removal}

Table 1 reveals that the $K_{S}$ values of Monod kinetic model for the COD removal in the Control-1 and Control-2 systems were significantly high. It is noted that the unit of $\mathrm{K}_{\mathrm{S}}$ for COD removal is $\mathrm{mg} \mathrm{COD} / \mathrm{L}$ and is typically high [20]. Furthermore, the influent COD concentration of $400 \mathrm{mg}$ COD/L was not significantly greater and lesser than the $K_{S}$; thus, the Monod model was best to describe the kinetics of COD removal in the Control-1 and Control-2 systems. It is notable that $E$. aerogenes was capable to degrade the organic matters at a slightly higher $\mathrm{k}_{2}$ than the mixed culture bacteria although the concentration of E. aerogenes $(\sim 266 \mathrm{mg}$ VSS/L) was considerably less than the concentration of mixed culture bacteria $(\sim 2,648 \mathrm{mg}$ VSS/L). The maximum specific COD biodegradation rates of mixed culture bacteria and $E$. aerogenes were 0.65 and $7.62 \mathrm{mg}$ COD/mg VSS-day, respectively. It is suggested that $E$. aerogenes degraded COD at a higher rate than the mixed culture bacteria. However, the $\mathrm{K}_{\mathrm{S}}$ values in Table 1 indicate that $E$. aerogenes had lower affinity for the synthetic wastewater than the mixed culture bacteria from the Control-2 system.

\subsection{Kinetics of Nitrification, $A M$ and $C O D$ Removals in Experimental SBR Systems}

Jangkorn et al. [9] reported that both AM-1 and AM-2 SBR systems completely removed the AM only at the dosages of 100 and 200 mg AM/L. However, the COD removal efficiencies in the AM-1 system decreased considerably after the AM addition as compared with the Control-1 system because amidase was required for mixed culture bacteria to degrade AM. The efficiencies subsequently increased with time in the AM-1 system after mixed culture bacteria were acclimatized with AM. As the AM concentrations increased to 300 and $400 \mathrm{mg} \mathrm{AM} / \mathrm{L}$, the AM removal efficiencies decreased considerably due to the inhibition of the free ammonia nitrogen (FAN). The FAN as one of the AM biodegradation products was accumulated in the SBR systems due to the failures of autotrophic and heterotrophic nitrifications in the AM-1 and AM-2 systems, respectively. The FAN also inhibited autotrophic nitrification of mixed culture bacteria. The accumulation of intracellular polyphosphate inhibited the heterotrophic nitrification of $E$. aerogenes. The FAN was reported as an inhibitor of amidase [21]. 
Table 3. Parameters of Monod No-growth Model for Acrylamide and COD Removals in the AM-1 and AM-2 Systems

\begin{tabular}{|c|c|c|c|c|c|c|c|c|c|}
\hline \multirow{2}{*}{ System } & \multirow{2}{*}{ A } & \multicolumn{4}{|c|}{ Acrylamide } & \multicolumn{4}{|c|}{ COD } \\
\hline & & B & Value & $\mathbf{R}^{2}$ & $\chi^{2}$ & B & Value & $\mathbf{R}^{2}$ & $\chi^{2}$ \\
\hline \multirow[t]{6}{*}{ AM-1 } & 100 & $\mathrm{k}_{2}$ & 25.9 & \multirow{2}{*}{1.000} & \multirow{2}{*}{28.5} & * & \multirow[t]{2}{*}{-} & \multirow[t]{2}{*}{-} & \multirow[t]{2}{*}{-} \\
\hline & & $\mathrm{K}_{\mathrm{S}}$ & 23.4 & & & & & & \\
\hline & \multirow[t]{2}{*}{200} & $\mathrm{k}_{2}$ & 40.8 & \multirow{2}{*}{1.000} & \multirow{2}{*}{150.2} & $\mathrm{k}_{2}$ & 43.9 & \multirow{2}{*}{1.000} & \multirow{2}{*}{19.1} \\
\hline & & $\mathrm{K}_{\mathrm{S}}$ & 34.9 & & & $\mathrm{~K}_{\mathrm{S}}$ & 68.4 & & \\
\hline & 300 & $*$ & - & - & - & * & - & - & - \\
\hline & 400 & $*$ & - & - & - & * & - & - & - \\
\hline \multirow[t]{6}{*}{ AM-2 } & 100 & $\mathrm{k}_{2}$ & 30.9 & \multirow{2}{*}{1.000} & \multirow{2}{*}{4.1} & * & \multirow[t]{2}{*}{-} & \multirow[t]{2}{*}{-} & \multirow[t]{2}{*}{-} \\
\hline & & $\mathrm{K}_{\mathrm{S}}$ & 28.4 & & & & & & \\
\hline & 200 & $\mathrm{k}_{2}$ & 49.6 & \multirow{2}{*}{1.000} & \multirow{2}{*}{100.2} & * & \multirow[t]{2}{*}{-} & \multirow[t]{2}{*}{-} & \multirow[t]{2}{*}{-} \\
\hline & & $\mathrm{K}_{\mathrm{S}}$ & 50.3 & & & & & & \\
\hline & 300 & $*$ & - & - & - & * & - & - & - \\
\hline & 400 & $*$ & - & - & - & * & - & - & - \\
\hline
\end{tabular}

* indicates unidentified kinetic parameters; A is acrylamide concentration (mg AM/L); B is Monod kinetic parameters.

\subsubsection{Kinetics of $A M$ biodegradation}

It can be seen from Table 3 that the AM biodegradations of mixed culture bacteria and E. aerogenes followed the Monod no-growth model at the AM concentrations of 100 and $200 \mathrm{mg} \mathrm{AM/L.} \mathrm{From}$ the Monod kinetic parameters in Table 3, it was found that the maximum AM biodegradation rate $\left(\mathrm{k}_{2}\right)$ and half saturation coefficient $\left(\mathrm{K}_{\mathrm{S}}\right)$ of $E$. aerogenes were higher than the mixed culture bacteria. The maximum specific AM biodegradation rates of mixed culture bacteria and E. aerogenes were 0.23 and $2.51 \mathrm{mg} \mathrm{AM} / \mathrm{mg}$ VSS-day, respectively, at the AM feeding concentration of 100 mg AM/L. At the AM concentration of $200 \mathrm{mg} \mathrm{AM} / \mathrm{L}$, the maximum specific AM biodegradation rates of mixed culture bacteria and E. aerogenes increased to 0.37 and $4.04 \mathrm{mg}$ AM/mg VSS-day, respectively. It appears that $E$. aerogenes degraded AM at a greater rate than mixed culture bacteria. Furthermore, E. aerogenes had less affinity for AM than mixed culture bacteria, suggesting a binding strength between amidase and AM of mixed culture bacteria was greater than E. aerogenes. Furthermore, both $\mathrm{k}_{2}$ and $\mathrm{K}_{\mathrm{S}}$ parameters in both AM-1 and AM-2 systems increased as the AM concentrations increased in the wastewater from 100 to 200 mg $\mathrm{AM} / \mathrm{L}$; in other words, the fraction of $\mathrm{AM}$ to other carbon sources increased in the synthetic wastewater. Subsequent addition of AM at higher dosages, the Monod no-growth kinetic parameters could not be identified in the AM- 1 and AM-2 systems at the AM feeding concentrations of 300 and $400 \mathrm{mg} \mathrm{AM} / \mathrm{L}$. To compare the Monod kinetic parameters between different AM concentrations, the initial AM concentrations during the AM feeding concentrations of 300 and $400 \mathrm{mg} \mathrm{AM} / \mathrm{L}$ were used as upper constraints for the parameter estimations of AQUASIM. It was found that the $\mathrm{K}_{\mathrm{S}}$ values of all SBR systems were equal to the upper constraint concentrations used during the estimations. Fig. 1 summarizes the changes of Monod kinetic parameters $\left(K_{S}\right.$ and $\mathrm{k}_{2}$ ) and the ammonium concentrations obtained at the end of reacting period of $10 \mathrm{~h}$ with different $\mathrm{AM}$ feeding concentrations. The results of parameter estimation as shown in Fig.1 indicate
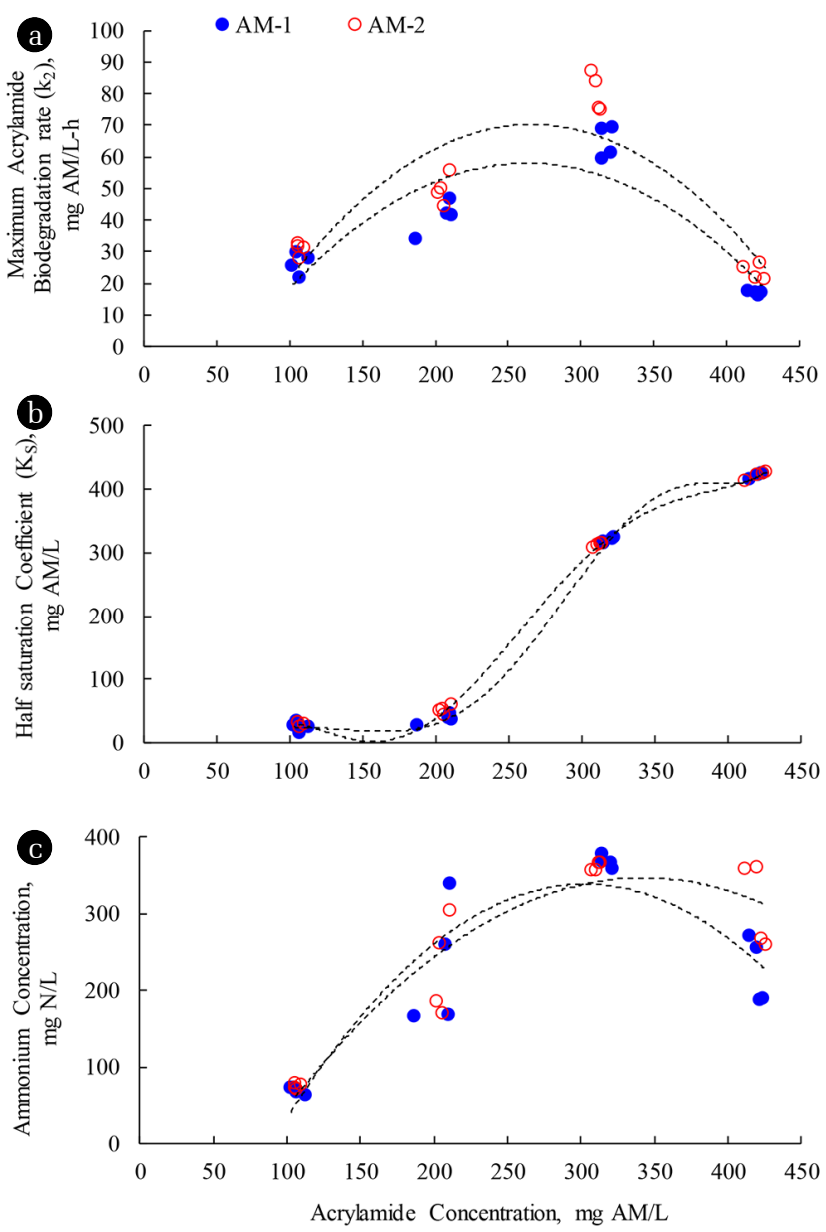

Fig. 1. Changes of (a) $k_{2}$ and (b) $K_{s}$ Monod kinetic parameters and (c) ammonium concentrations at the end reacting period with different acrylamide concentrations. 
that both $\mathrm{k}_{2}$ and $\mathrm{K}_{\mathrm{S}}$ increased with the AM concentrations in all SBR systems during the AM feeding concentrations of 100-300 mg AM/L. It possibly explains that the addition of AA from the AM biodegradation into the wastewater produced a more complex nature of mixed substrates, which the microbes had low affinity (high $\mathrm{K}_{\mathrm{S}}$ ) with these mixed substrates [19]. Furthermore, when the proportion of AM increased in the synthetic wastewater, the amount of amidase increased accordingly so higher values of $\mathrm{k}_{2}$ for AM utilization were achieved. However, when AM was fed at the concentration of $400 \mathrm{mg} \mathrm{AM} / \mathrm{L}$ in the AM- 1 and AM-2 systems, the $\mathrm{K}_{\mathrm{S}}$ tremendously increased with the significant decreases of $\mathrm{k}_{2}$, suggesting that the AM biodegradation was inhibited.

The experimental results revealed that the ammonium considerably accumulated during the AM feeding concentration of 300 mg AM/L in the AM-1 and AM-2 systems, resulting in the FAN remaining in the systems. It was explained from the experiments that the small fraction of the FAN in the solutions reduced the affinity of microorganisms for AM. It is unlikely that the AM biodegradation was inhibited due to the toxicity of AM as substrate inhibition. It was evident from the batch studies [9] that both the mixed culture bacteria and E. aerogenes without AM acclimatization could remove AM at the removal efficiencies of 65.2 and 73.7\%, respectively, at the AM concentration of $400 \mathrm{mg} \mathrm{AM} / \mathrm{L}$ without any other carbon sources. Also, it was reported that $E$. aerogenes could be cultured in the media with the AM concentration of 5,000 mg AM/L without any inhibition [5]. However, the accumulation of ammonium has not been reported in any AM biodegradation studies in the culture media. For the parameter estimations of both $\mathrm{k}_{2}$ and $\mathrm{K}_{\mathrm{S}}$ during the AM feeding concentrations of 300 and $400 \mathrm{mg} \mathrm{AM} / \mathrm{L}$, Table 3 indicates that both parameters could not be identified because $\mathrm{K}_{\mathrm{S}}$ increased tremendously. It suggests that the AM biodegradation rate approaches the first-order approximation.

The first-order approximations by the linear regressions of graphical plots between AM concentrations and time for the AM biodegradations of AM-1 and AM-2 systems feeding with different AM feeding concentrations of 100, 200, 300 and $400 \mathrm{mg} \mathrm{AM/L}$ were evaluated and are illustrated in Fig. 2(a) and 3(a), respectively. The graphical plots of first-order approximation for the AM biodegradation at the AM concentrations of 100 and $200 \mathrm{mg} \mathrm{AM} / \mathrm{L}$ reveal the failures of fitting data points to the linear lines. The concave-down profile between natural logarithm of concentration and time generally indicates that the Monod kinetics was applied. As listed in Table 3 at the AM feeding concentrations of 300 and $400 \mathrm{mg}$ AM/L, the Monod kinetic parameters could not be identified and the first-order reaction was suggested for the AM biodegradation as the $\mathrm{K}_{\mathrm{S}}$ increased considerably due to the FAN inhibition. The first-order rates for AM biodegradation at the AM feeding concentrations of $100,200,300$, and $400 \mathrm{mg}$ AM/L of the AM-1 and AM-2 systems could be obtained from the slopes of straight lines in Fig. 2(a) and 3(a), respectively. It is noted that the $R^{2}$ values of lower than 0.90 were obtained from the first-order approximations of AM-1 and AM-2 systems at the AM concentration of $400 \mathrm{mg} \mathrm{AM/L}$ because the linear lines were approaching horizontal level, indicating that very low biodegradation was obtained. The data points lied exactly on the linear lines. Furthermore, it is confirmed that the FAN inhibited the AM biodegradation because the first-order

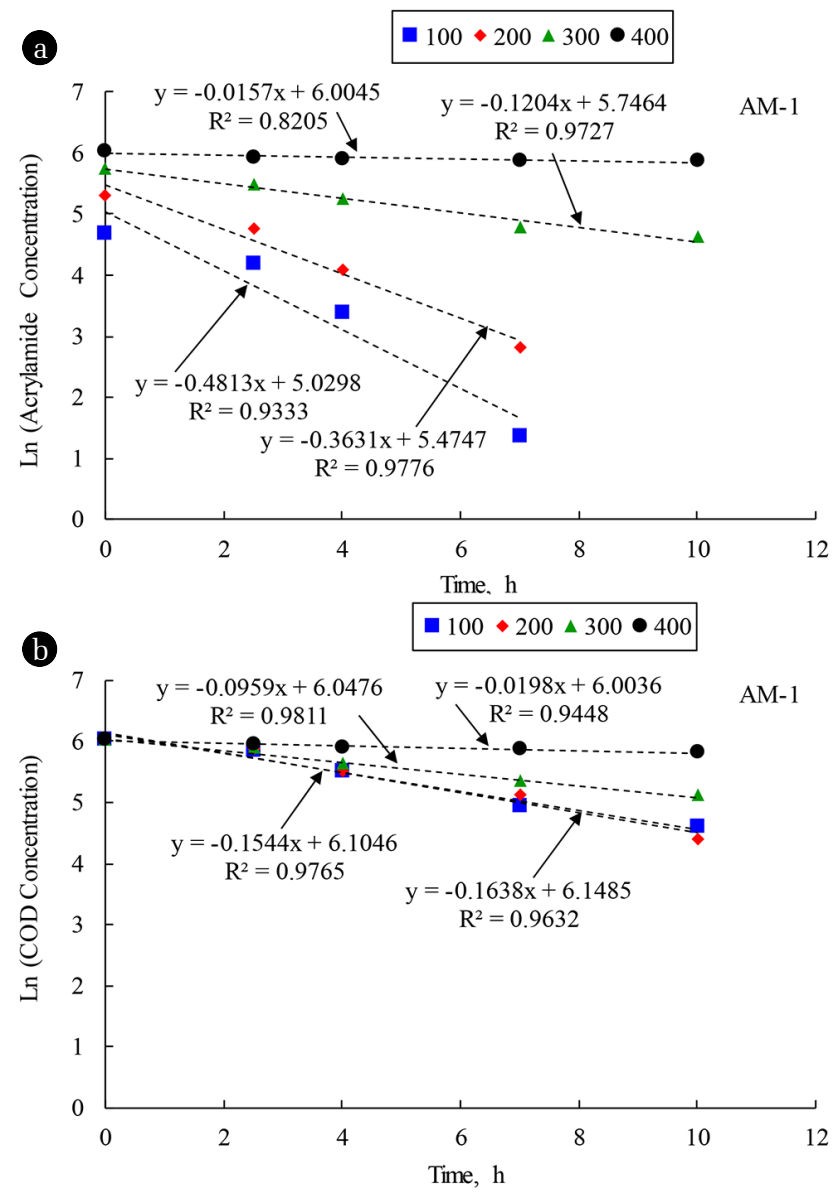

Fig. 2. Natural logarithm of concentration versus time of first-order reactions for (a) acrylamide and (b) COD removals in the AM-1 system at the acrylamide concentrations of 100, 200, 300, and $400 \mathrm{mg} \mathrm{AM} / \mathrm{L}$.

rates decreased significantly as the AM concentration increased in the synthetic wastewater more than $200 \mathrm{mg} A M / L$ in the $\mathrm{AM}-1$ and AM-2 systems.

In summary, Monod no-growth model could describe the kinetics of AM biodegradation by mixed culture bacteria and $E$. aerogenes at low AM concentrations of 100 and $200 \mathrm{mg} \mathrm{AM} / \mathrm{L}$. Higher AM in the synthetic wastewater resulted in the transformation of kinetic model from the Monod no-growth model to first-order approximation due to the FAN inhibition. The kinetic evaluations of first-order approximation for AM biodegradation indicate that $E$. aerogenes was superior to the mixed culture bacteria for the AM biodegradation.

\subsubsection{Effects of $A M$ on the kinetics of COD removal}

The kinetics of COD removal by different microorganisms were evaluated at different fractions of AM in the synthetic wastewater. The results of Monod kinetic parameter estimations are listed in Table 3. For the AM-1 system containing mixed culture bacteria, it indicates that Monod kinetic parameters at the AM feeding concentration of $100 \mathrm{mg} \mathrm{AM} / \mathrm{L}$ could not be identified because the $\mathrm{K}_{\mathrm{S}}$ was considerably high, indicating very low affinity of mixed 


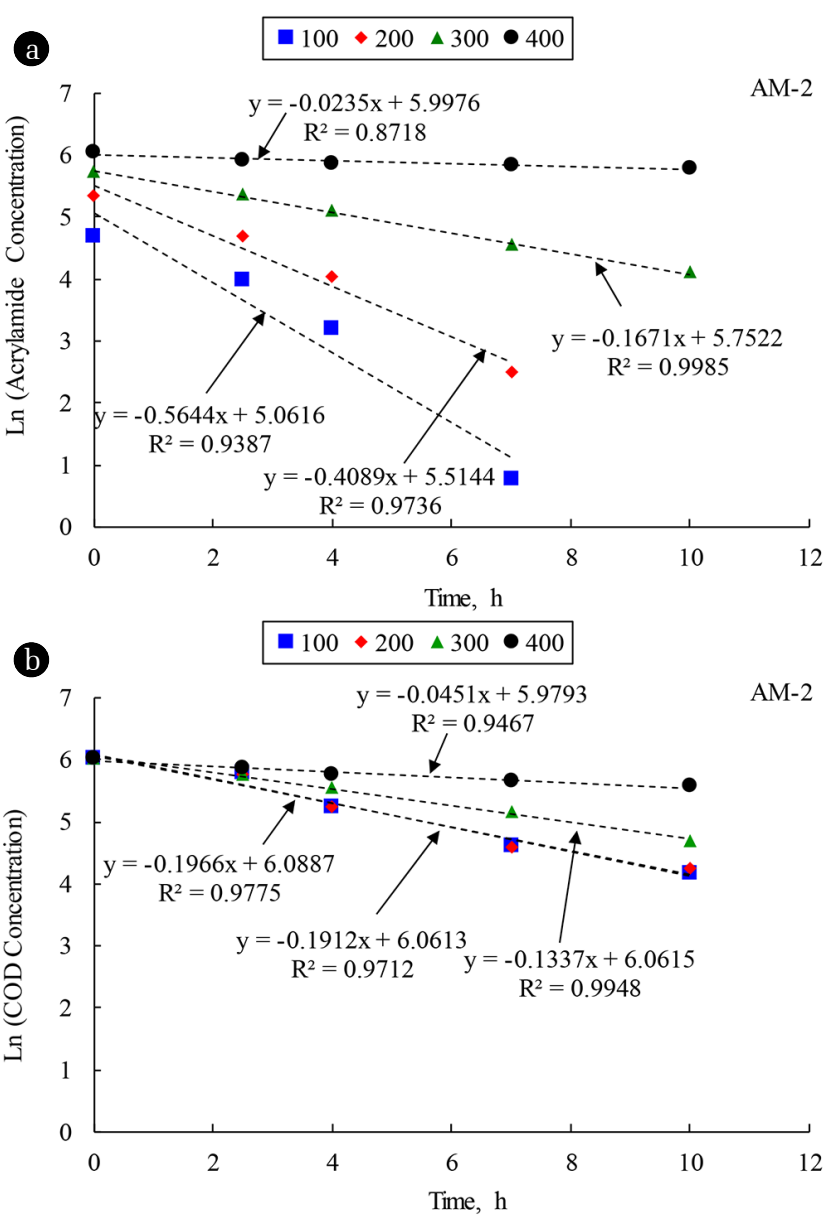

Fig. 3. Natural logarithm of concentration versus time of first-order reactions for (a) acrylamide and (b) COD removals in the AM-2 system at the acrylamide concentrations of 100, 200, 300, and $400 \mathrm{mg} \mathrm{AM} / \mathrm{L}$.

culture bacteria for COD as a result of AM addition. It was found from the experimental results [9] that the COD removal efficiencies increased with time because the acclimatization of mixed culture bacteria to the AM addition was required. Amidase was required for the mixed culture bacteria to biodegrade the AM. After the mixed culture bacteria was acclimatized with AM, the COD removal kinetics could be best described by the Monod no-growth model during the AM feeding concentration of $200 \mathrm{mg} \mathrm{AM} / \mathrm{L}$ $\left(\mathrm{k}_{2}=43.9 \mathrm{mg} \mathrm{COD} / \mathrm{L}-\mathrm{h}, \mathrm{K}_{\mathrm{S}}=68.4 \mathrm{mg} \mathrm{COD} / \mathrm{L}\right)$. Significant reductions of both $\mathrm{k}_{2}$ and $\mathrm{K}_{\mathrm{S}}$ were obtained as compared with the Monod kinetic parameters for the COD removal in the Control-1 system ( $\mathrm{k}_{2}=71.6 \mathrm{mg}$ COD/L-h, $\mathrm{K}_{\mathrm{S}}=230.3 \mathrm{mg}$ COD/L). It appears that the ability of mixed culture bacteria to scavenge the COD was improved as indicated by the reductions of both $\mathrm{K}_{\mathrm{S}}$ and $\mathrm{k}_{2}$ [19]. However, when the AM concentrations increased in the synthetic wastewater to 300 and $400 \mathrm{mg} \mathrm{AM} / \mathrm{L}$, respectively, the substrate affinity of the mixed culture bacteria decreased significantly again. It explains that the additions of both AM and AA from the AM biodegradation in the wastewater at higher loadings, creating a different composition of mixed substrates, reduced the affinity of mixed culture bacteria for the mixed substrates. In addition, the FAN began to inhibit the AM biodegradation at the AM concentration of $400 \mathrm{mg}$ AM/L. The Monod kinetic parameters could not be identified, indicating that the first-order model was best described for the COD removal in the AM-1 system.

In contrast to the AM-1 system, the substrate affinity of $E$. aerogenes for COD decreased suddenly as both AM and AA increased in the synthetic wastewater. It means that there were some changes in the physiological states of E. aerogenes cells when the AM and AA increased in the synthetic wastewater [19]. As the AM concentration increased incrementally to $400 \mathrm{mg} A M / L$, the $\mathrm{K}_{\mathrm{S}}$ increased considerably, resulting in the transformation of Monod kinetic model to the first-order model as the effects of FAN inhibition began to inhibit the AM biodegradation.

The first-order approximations of the COD removal in the AM-1 and AM-2 systems were evaluated from the slopes of straight lines in Fig. 2(b) and 3(b), respectively. It was found that the COD removal rates were much lower than the AM biodegradation rates because the COD is a non-specific parameters to represent the mixed substrates in the synthetic wastewater. The first-order rates also indicate that $E$. aerogenes could remove the COD at faster rate than the mixed culture bacteria as a result of less interactions among microorganisms in the pure culture.

\subsubsection{Effects of $A M$ on the nitrification kinetics}

The experimental results revealed that ammonium was accumulated in both AM-1 and AM-2 systems due to the AM biodegradation [9]; thereby, nitrification kinetics could not be determined because both nitrification and ammonium production occurred simultaneously. To evaluate the effects of AM loadings on the nitrification kinetics indirectly. Jangkorn et al. [9] proposed to employ the nitrate production rates to represent the heterotrophic and autotrophic nitrifications of E. aerogenes and mixed culture bacteria, respectively. It is noted that the studies were conducted in purely aerobic systems so that denitrification was negligible and nitrite and nitrate were remained constant in the solution. They found that the nitrate and nitrite productions of both mixed culture bacteria and E. aerogenes followed the zero-order kinetics as indicated by the average $R^{2}$ value of 0.97 .

Table 4 lists the zero-order nitrite and nitrate production rates of both mixed culture bacteria in the Control-1 and AM-1 systems and E. aerogenes in the Control-2 and AM-2 systems. It could be interpreted from the nitrite and nitrate production rates in Table 4 that the nitrification rates in the AM-1 and AM-2 systems were greater than the nitrifications in the Control-1 and Control-2 systems. It explains that both microbes increased ammonium in the solution from the AM biodegradation, increasing the nitrification rates of both bacteria as compared with the control systems. However, when the AM concentrations increased from $100 \mathrm{mg} \mathrm{N} / \mathrm{L}$ to $300 \mathrm{mg} \mathrm{N} / \mathrm{L}$, the ammonium nitrogen concentration increased dramatically, but the nitrite and nitrate production rates of the mixed culture bacteria in the AM-1 system decreased gradually. In contrast, the nitrate production rates of E. aerogenes in the AM-2 system increased. It was explained by Jangkorn et al. [9] that nitratation in the AM-1 system was inhibited by the FAN, but heterotrophic nitrification of $E$. aerogenes in the AM-2 system was not affected by this inhibitor. At the AM concentration 
Table 4. Average Zero-order Nitrite and Nitrate Production Rates in the AM-1 and AM-2 Systems

\begin{tabular}{|c|c|c|c|c|c|}
\hline Substance & $\begin{array}{l}\text { AM Concentration } \\
\text { (mg AM/L) }\end{array}$ & $\begin{array}{l}\text { Control-1 } \\
\text { (mg N/L-h) }\end{array}$ & $\begin{array}{c}\text { AM-1 } \\
\text { (mg N/L-h) }\end{array}$ & $\begin{array}{l}\text { Control-2 } \\
\text { (mg N/L-h) }\end{array}$ & $\begin{array}{c}\text { AM-2 } \\
\text { (mg N/L-h) }\end{array}$ \\
\hline \multirow{4}{*}{ Nitrate } & 100 & \multirow{4}{*}{$1.09(0.968)$} & $1.44(0.931)$ & \multirow{4}{*}{$0.57(0.993)$} & $1.41(0.976)$ \\
\hline & 200 & & $1.23(0.982)$ & & $1.76(0.976)$ \\
\hline & 300 & & $1.32(0.985)$ & & $1.63(0.978)$ \\
\hline & 400 & & $0.57(0.924)$ & & $0.40(0.955)$ \\
\hline \multirow{4}{*}{ Nitrite } & 100 & \multirow{4}{*}{$0.16(0.941)$} & $0.58(0.988)$ & \multirow{4}{*}{$0.20(0.907)$} & $0.70(0.969)$ \\
\hline & 200 & & $0.42(0.987)$ & & $0.43(0.941)$ \\
\hline & 300 & & $0.29(0.973)$ & & $0.44(0.931)$ \\
\hline & 400 & & $0.23(0.975)$ & & $0.28(0.970)$ \\
\hline
\end{tabular}

Number in the parenthesis is the $\mathrm{R}^{2}$ values

of $400 \mathrm{mg} \mathrm{AM} / \mathrm{L}$, both AM biodegradation and autotrophic nitrification were inhibited by the FAN, reducing the nitrification rates in the AM-1 system. The accumulation of intracellular polyphosphate of $E$. aerogenes reduced the nitrite and nitrate production rates in the AM-2 system.

\section{Conclusions}

Three biodegradation models including Monod no-growth, zero-order and first-order kinetic models were employed to evaluate the effects of AM loadings on the AM and COD removals and nitrification kinetics of the mixed culture bacteria and $E$. aerogenes in the biological wastewater treatment systems. The nitrification, AM biodegradation, and COD removal of both mixed culture bacteria and E. aerogenes were best described by the Monod kinetic model. The first-order expression was selected for the heterotrophic nitrification of $E$. aerogenes with the accumulation of intracellular polyphosphate granules. The transformation of Monod kinetics for AM and COD removals to the first-order kinetics due to the FAN inhibition occurred at high AM concentration $400 \mathrm{mg}$ AM/L. The kinetics indicated that $E$. aerogenes biodegraded the AM and COD at higher rate than the mixed culture bacteria. At the AM concentrations of 100-300 mg AM/L, both heterotrophic and autotrophic nitrification rates increased due to the addition of ammonia from the AM biodegradation. At higher AM loading, the FAN inhibited the autotrophic nitrification and reduced the nitrification rates. On the other hand, the accumulation of intracellular polyphosphate reduced the heterotrophic nitrification rates.

\section{Acknowledgments}

The authors are grateful for all financial supports from the Research Funds of Burapha University through National Research Council of Thailand [grant number 122/2558] to Tongchai Sriwiriyarat and the Office of the Higher Education Commission (OHEC), Ministry of Education, Thailand through a Ph.D. scholarship to Romsan Madmanang.

\section{References}

1. US EPA. Toxicological review of acrylamide. Washington D.C.: U.S. Environmental Protection Agency; 2010. p. 5.

2. Charoenpanich J. Removal of acrylamide by microorganisms. In: Patil YB, Rao P, eds. Applied bioremediation-active and passive approaches. Croatia: InTech Open Science Online Publishers; 2013. p. 101-121.

3. Prabu CS, Thatheyus AJ. Biodegradation of acrylamide employing free and immobilized cells of Pseudomonas aeruginosa. Int. Biodeter. Biodegr. 2007;60:69-73.

4. Shanker R, Ramakrishna C, Seth PK. Microbial degradation of acrylamide monomer. Arch. Microbiol. 1990;154:192-198.

5. Buranasilp K, Charoenpanich J. Biodegradation of acrylamide by Enterobacter aerogenes isolated from wastewater in Thailand. J. Environ. Sci-China. 2011;23:396-403.

6. Hormaeche E, Edwards PR. A proposed genus Enterobacter. Int. Bull. Bacteriol. Nomenclature Taxonomy 1960;10:71-74.

7. Asadi N, Zilouei H. Optimization of organosolv pretreatment of rice straw for enhanced biohydrogen production using Enterobacter aerogenes. Bioresour. Technol. 2017;227:335-344.

8. Robertson GP, Groffman PM. Nitrogen transformations. In: Paul EA, ed. Soil microbiology, ecology and biochemistry. Massachusetts: Academic Press; 2007. p. 352.

9. Jangkorn J, Charoenpanich J, Sriwiriyarat T. Comparative study between Enterobacter aerogenes and mixed culture bacteria for acrylamide biodegradation in sequencing batch reactor (SBR) wastewater treatment systems. J. Environ. Eng. 2018;144: 04017112.

10. Zhao L, Bao M, Yan M, Lu J. Kinetics and thermodynamics of biodegradation of hydrolyzed polyacrylamide under anaerobic and aerobic conditions. Bioresour. Technol. 2016;216:95-104.

11. Battersby NS. A review of biodegradation kinetics in the aquatic environment. Chemosphere 1990;21:1243-1284.

12. Orhon D, Artan N. Reactor kinetics of microbial processes. In: Orhon D, Artan N, eds. Modelling of activated sludge systems. Pennsylvania: Technomic Publishing; 1994. p. 121-122.

13. Alexander M. Kinetics. In: Alexander M, ed. Biodegradation and bioremediation. California: Academic Press; 1999. p. 
81-83.

14. Reichert P. AQUASIM - A tool for simulation and data analysis of aquatic systems. Water Sci. Technol. 1994;30:21-30.

15. Lin YM, Tay JH, Liu Y, Hung YT. Biological nitrification and denitrification process. In: Wang LK, Pereira NC, Hung YT, eds. Biological treatment processes. New York: Humana Press; 2009. p. 569-570.

16. Harold FM. Accumulation of inorganic polyphosphate in Aerobacter aerogenes. I. Relationship to growth and nucleic acid synthesis. J. Bacteriol. 1963;86:216-221.

17. Henze M, Grady CPL, Gujer W, Marais GVR, Matsuo T. A general model for single sludge wastewater treatment systems. Water Res. 1987;21:505-515.

18. Kayee P, Rongsayamanont C, Kunapongkiti P, Limpiyakorn
T. Ammonia half-saturation constants of sludge with different community compositions of ammonia-oxidizing bacteria. Environ. Eng. Res. 2016;21:140-144.

19. Kovárová-Kovar K, Egli T. Growth kinetics of suspended microbial cells: From single-substrate-controlled growth to mixed-substrate kinetics. Microbiol. Mol. Biol. Rev. 1998;62:646-666.

20. van Niel EWJ, Arts PAM, Wesselink BJ, Robertson LA, Kuenen JG. Competition between heterotrophic and autotrophic nitrifiers for ammonia in chemostat cultures. FEMS Microbiol. Ecol. 1993;102:109-118.

21. Schomburg D, Salzmann M. Amidase. In: Schomburg D, Salzmann M, eds. Enzyme handbook 4, class 3: hydrolases. New York: Springer-Verlag Berlin Heidelberg GmbH; 1991. p. 667-671. 